\title{
"Os segredos da carne": o mercado atlântico das carnes secas e salgadas e a influência da matriz irlandesa de fabricação no extremo sul da América Latina (c. 1780 - c. 1820)
} Jonas Moreira Vargas*

Resumo: Durante o colonial tardio, Pelotas (no Rio Grande do Sul), Buenos Aires e Montevideu destacaram-se economicamente por reunirem vários estabelecimentos produtores de carne-seca destinados a abastecer a crescente demanda por alimentos que caracterizou o período. Mas antes disso, e utilizando-se de técnicas distintas, a Irlanda tinha notável importância na fabricação e comércio de carnes salgadas no Atlântico. O presente artigo busca demonstrar, dentro do contexto socioeconômico da época, a influência e a presença de irlandeses no Rio da Prata e Rio Grande do Sul, prontos a ensinarem os colonos locais, a disputa entre as matrizes irlandesa e nativa no preparo de carnes e a história de alguns dos investidores neste ramo de negócios.

Palavras-chave: Charque. Comércio atlântico. Escravidão. Rio da Prata.

De acordo com os dados disponíveis no site www.slavevoyages. org, entre 1776 e 1825 foram desembarcados nos portos das Américas quase 3,5 milhões de escravos africanos. Tal índice de cativos trazidos

\footnotetext{
* Doutor em História Social pela Universidade Federal do Rio de Janeiro - UFRJ. Professor adjunto do Departamento de História da Universidade Federal de Pelotas - UFPel. E-mail: jonasmvargas@yahoo.com.br
}

Anos 90, Porto Alegre, v. 24, n. 45, p. 153-182, jul. 2017 
"Os segredos da carne": o mercado atlântico das carnes secas...

no espaço de 50 anos representou, aproximadamente, $1 / 3$ do total de africanos que cruzaram o oceano via comércio negreiro, entre 1500 e $1850^{1}$, ou seja, tratava-se do mais intenso fluxo de escravos levados para as Américas, refletindo que aquele foi um período de notável desenvolvimento da economia em diferentes setores de ambos os lados do Atlântico. Naquele contexto, a montagem de milhares de plantations algodoeiras, açucareiras e cafeeiras nas Américas - que vinham atender direta e indiretamente a demanda europeia causada pela Revolução Industrial e os estímulos metropolitanos para o desenvolvimento da economia colonial - promoveu este intenso tráfico de escravos para as colônias britânicas, francesas e ibéricas, dinamizando e conectando distintos espaços econômicos de trocas. Como consequência desse rápido crescimento populacional que marcou o período e da necessidade de alimentar o enorme contingente de escravos que vinham sendo desembarcados, não apenas Pelotas e Montevideu (na década de 1780) como também Buenos Aires (após 1810) se destacaram como os principais centros produtores de carne-seca e salgada da América do Sul (Figura 1). ${ }^{2}$

Como argumentou Bertie Mandelblatt é necessário que se deixe de ver os escravos africanos no mundo atlântico somente como trabalhadores e como mercadorias, passando a pensá-los também como consumidores (MANDELBLATT, 2007, p. 21). Seguindo estas premissas, pode-se perceber a ligação do charque com a manutenção do tráfico atlântico e da escravidão a partir de uma tripla relação. Ao mesmo tempo em que a mão de obra cativa foi essencial para a montagem das charqueadas e saladeros em Pelotas e no Rio da Prata, a crescente escravaria das numerosas plantations atlânticas fazia aumentar a demanda pelo produto. Além disso, por se tratar de um alimento resistente à deterioração e conservável por muitos meses, o charque também acompanhava as tripulações dos negreiros que cruzavam o Atlântico garantindo os suprimentos dos escravos no retorno de suas viagens (SLUYTER, 2010; FLORENTINO, 1997, p. 122-125; VARGAS, 2013, p. 94). 
Figura 1 - Localização de Pelotas, Montevideu e Buenos Aires no espaço fronteiriço do cone sul americano (século XIX)

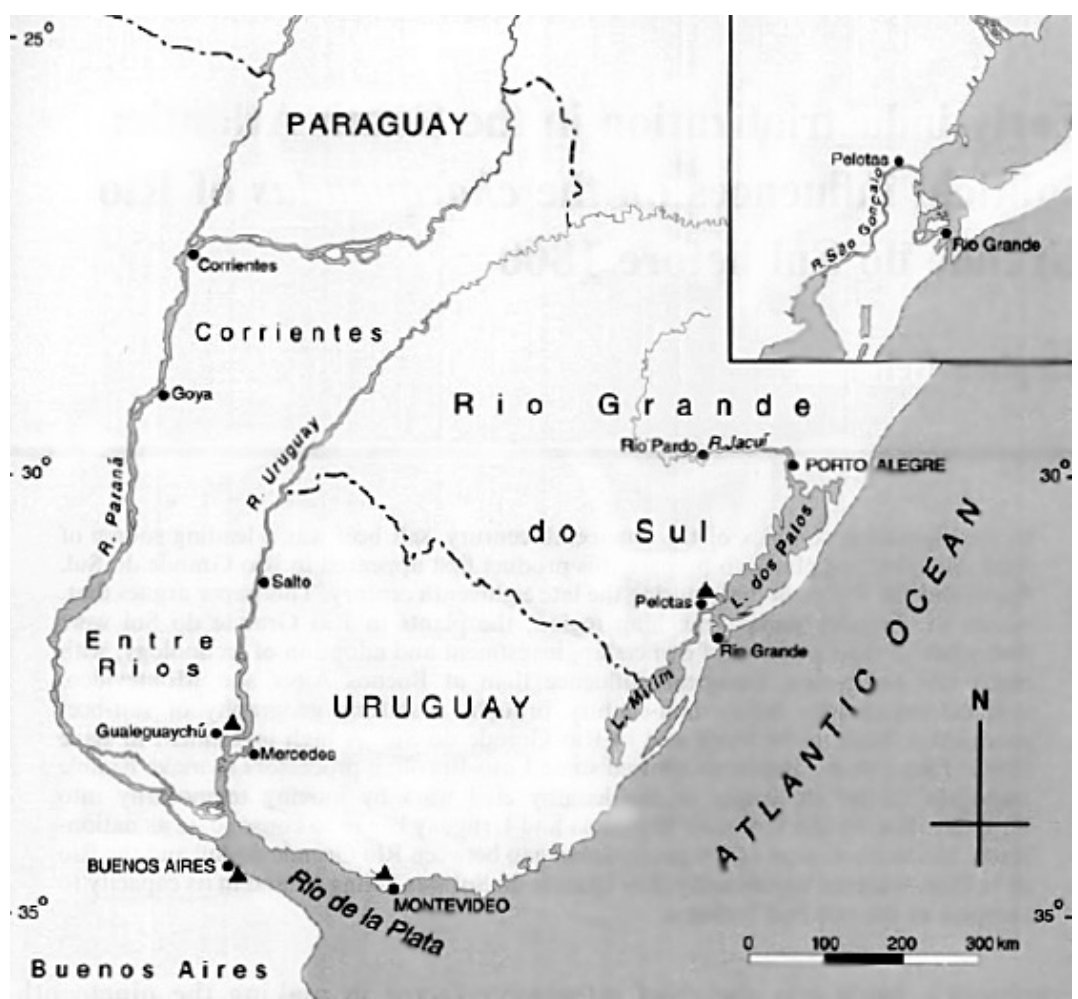

Fonte: BELL (1993, p. 400).

Para Andrew Sluyter, esta rota mercantil de charque (ou tasajo, para os platinos) que ligava o Rio da Prata à Cuba, por exemplo, conectava duas regiões e duas atividades produtivas na qual a escravidão africana era fundamental, criando um circuito mercantil lucrativo no qual a mercadoria principal, o tasajo, era fabricado, principalmente, "por" e "para" trabalhadores cativos. Neste contexto, 
"Os segredos da carne": o mercado atlântico das carnes secas...

a importação de escravos para Pelotas, Montevidéu e Buenos Aires também fez parte de um mesmo processo no qual a ampliação do tráfico atlântico, a montagem das novas plantations e a produção de gêneros alimentícios estavam intimamente conectadas. ${ }^{3}$ Sluyter chamou esse novo circuito mercantil de tasajo trail e, embora o autor tenha pesquisado somente a produção de carnes em Buenos Aires, esta rota também envolvia as carnes preparadas em Montevidéu e em Pelotas. Para o autor, o tasajo trail ajudou a sustentar os mais proeminentes fluxos mercantis de açúcar e escravos que definiram a própria compreensão do mundo atlântico no período (SLUYTER, 2010, p. 101). Portanto, a necessidade de se estudar esses espaços produtores de alimentos deixa de ser algo pouco importante para o estudo dos sistemas econômicos atlânticos e passa a ocupar um lugar fundamental de análise.

O processo de salga da carne para a sua conservação é bastante antigo e era conhecido por diferentes povos em várias partes do mundo. Contudo, a constituição de um espaço regional dedicado a tais atividades econômicas em enorme escala (com a finalidade de obter lucros no mercado externo), o emprego de um enorme contingente de trabalhadores em moldes fabris e a consequente transformação da paisagem rural no qual o mesmo se situava, caracterizou poucas localidades. Uma delas foi a Irlanda, que teve nos centros fabris de Belfast, Cork e Dublin vigorosos espaços de produção e comércio de carne salgada - fenômeno que marcou o mundo atlântico no século XVIII. Conhecedoras do protagonismo irlandês, as Coroas ibéricas estimularam as suas respectivas colônias ao sul da América para que investissem em tais negócios, buscando uma autossuficiência neste ramo. A abundância de bovinos nas vastas pastagens da Bacia do Prata e a necessidade de abastecer as escravarias das crescentes plantations açucareiras e as tripulações das Marinhas metropolitanas favoreceriam tal empreendimento.

Contudo, a forma como os irlandeses preparavam a carne com fins de conservá-la diferia bastante de outras práticas mais usuais entre os colonos sul-americanos. Os irlandeses preparavam e condicionavam as suas carnes em barris, no qual a mercadoria ficava imersa numa espécie de salmoura. Tal método exigia um contínuo abastecimento de barris e técnicas de preparo bastante 
meticulosas, sendo que poucos obtinham sucesso na sua fabricação. Ao que parece era um alimento comum nas tripulações das embarcações que navegavam o Atlântico norte, mas também utilizado no abastecimento das plantations antilhanas. Essa mercadoria era conhecida como "carne em barris", "carne salgada", "carne de moura" ou "carne em salmoura". Em contrapartida, a carne bovina cortada em finas mantas que posteriormente eram impregnadas de sal e colocadas ao sol para secar em compridos varais tratava-se de um produto distinto. $\mathrm{Na}$ América lusa, esse alimento era conhecido como charque ou carne-seca e na América platina como tasajo. Os próprios indígenas americanos conheciam essa forma de conservação e, ao longo de todo o século XVIII, antes que Pelotas surgisse como grande produtora, as capitanias do Ceará e do Piauí já fabricavam a mercadoria em larga escala. Foram as sucessivas secas dos anos 1770 e 1790 que eliminaram ambas as capitanias do norte deste mercado, abrindo espaço para os produtores pelotenses e platinos. ${ }^{4}$

$\mathrm{O}$ presente artigo busca analisar o contexto de montagem destes primeiros estabelecimentos em Pelotas e no Rio da Prata, com ênfase na influência irlandesa sobre a forma de se preparar as carnes para o mercado atlântico. Se por um lado as Coroas ibéricas tinham nessa matriz o seu ideal de mercadoria a ser fabricada pelos colonos empreendedores no ramo, por outro, estes não possuíam infraestrutura e a expertise necessárias para reproduzir em escala sul-americana o sucesso mercantil que os irlandeses obtiveram no Atlântico norte. Contudo, a escolha por fabricar a carne-seca em detrimento das carnes em barris também se explica pela autonomia dos colonos em decidir o melhor a cerca dos seus investimentos, tomando decisões econômicas de acordo com os seus interesses pessoais e as redes mercantis na qual estavam inseridos. Além disso, é importante ressaltar que comerciantes, saladeiristas e charqueadores agiam numa conjuntura de ampla difusão de ideias e trocas políticas e socioculturais intensas que caracterizaram o processo de independência das colônias americanas e que colocaram em contato indivíduos e ideias de distintas partes do Atlântico. A formação dos complexos fabris pelotenses e platinos no colonial tardio foi fruto deste processo. ${ }^{5}$

Anos 90, Porto Alegre, v. 24, n. 45, p. 153-182, jul. 2017 
"Os segredos da carne": o mercado atlântico das carnes secas...

\section{Os fabricantes irlandeses no mercado atlântico das carnes preparadas}

Muito antes do surgimento das oficinas de carne seca no norte da América portuguesa, das charqueadas de Pelotas e dos saladeros em Montevideu e Buenos Aires, o comércio atlântico de carnes preparadas já movimentava centenas de embarcações e viabilizava, por exemplo, o abastecimento das plantations caribenhas e das tripulações dos navios europeus. A partir de meados do século XVII, a Irlanda destacou-se na fabricação e no comércio destes gêneros, dominando o mercado atlântico durante boa parte do século posterior. No amplo circuíto mercantil do qual os comerciantes irlandeses faziam parte, o porto de Cork tornou-se o principal pólo fabril de carne salgada dos séculos XVII e XVIII, desenvolvendo o único sistema bancário considerável na Irlanda. Neste tempo, sua população multiplicou-se várias vezes, tornando a cidade uma das mais cosmopolitas da Europa (MANDELBLATT, 2007, p. 26). Uma análise do funcionamento desta rede mercantil, desde a sua formação até a sua decadência, é de fundamental importância para compreender o surgimento dos complexos charqueadores no extremo sul da América, tanto em Pelotas, quanto nas margens do Rio da Prata - em Buenos Aires e Montevidéu.

Região de vastas pastagens, a Irlanda já remetia seus rebanhos vacuns e barris de carne salgada para a Inglaterra, mesmo antes da montagem das plantations açucareiras no Caribe. Enquanto o gado era destinado para o abastecimento da população, as carnes preparadas tinham na Marinha inglesa a sua principal consumidora. Entre 1663 e 1664, por exemplo, a pequena ilha exportou mais de $76 \mathrm{mil}$ cabeças de gado para a Inglaterra. Contudo, a crescente importação de bovinos irlandeses, que caracterizou o conturbado período em que Oliver Cromwell esteve no poder, não vinha agradando os pecuaristas do norte da Inglaterra. Organizados, estes fizeram intensa pressão sobre o Parlamento britânico e conseguiram que o mesmo promulgasse leis para interromper a entrada do gado irlandês no Reino. Foram os Cattle Acts, sendo o primeiro de 1663 (que teve um caráter experimental de seis meses) e o segundo de 1667 (que decidiu pela proibição definitiva das importações). Estas medidas

Anos 90, Porto Alegre, v. 24, n. 45, p. 153-182, jul. 2017 
provocaram a baixa dos preços do gado na Irlanda, o que favoreceu o acesso dos pequenos comerciantes no ramo e a consequente ampliação do número de fábricas de carne salgada em Cork, Belfast e Dublin (OIMAIRE; GALLAGHER, 2011, p. 7).

O desenvolvimento da indústria das carnes salgadas também estimulou a expansão de outros ramos da economia atlântica. Como a colocação das carnes no mercado necessitava de uma grande quantitade de barris, a tanoaria irlandesa cresceu conjuntamente, movimentando a importação de madeiras, tanto do interior da Irlanda, como de outras regiões (as colônias inglesas no norte da América, por exemplo). Soma-se a isto o aumento da demanda por sal - produto indispensável no preparo das carnes - que tinha como principais fornedores a França, a Espanha e Portugal. Além de utilizado na salmoura da carne bovina, o sal também era empregado na salga da carne de porco e na conservação da manteiga, outros dois importantes produtos exportados pelos irlandeses (HORTA, 2005).

Com os Cattle Acts, os rebanhos irlandeses, anteriormente exportados para a Inglaterra, passaram a alimentar a crescente demanda das novas fábricas de carne. Se no meado do XVII o mercado consumidor das carnes salgadas ainda era relativamente pequeno, nas décadas seguintes o crescimento das exportações foi notável. Em 1665, o volume das remessas do produto dobrou com relação à década de 1640 e, em 1683, as exportações duplicaram novamente com relação aos anos 1660. Conforme Thomas Truxes, esta foi a fase de arranque da indústria de carnes irlandesa e, entre 1660 e 1688, nenhuma outra mercadoria negociada pelos portos das ilhas britânicas ultrapassou o volume exportado do produto (TRUXES, 1988, p. 26-27). Tal fenômeno estava diretamente relacionado ao desenvolvimento do comércio atlântico e à fase inicial da expansão das unidades açucareiras no Caribe, que provocaram o aumento da entrada de escravos para a região, assim como de colonos, mercadores e membros da burocracia. ${ }^{6}$ Além disso, a disponibilidade de grandes extensões de pastagens férteis e próximas das principais cidades portuárias irlandesas e a existência de uma rede de transportes interna bem desenvolvida foram fundamentais para baixar os custos da produção da carne salgada. Conforme Mandelblatt, a razão para o sucesso da carne irlandesa no mercado caribenho 
"Os segredos da carne": o mercado atlântico das carnes secas...

era o seu baixo custo em relação a outras fontes de abastecimento (MANDELBLAT'T, 2007, p. 26).

Passada a fase inicial de expansão, as exportações irlandesas continuaram crescendo ao longo do século XVIII. Na década de 1710 , pela primeira vez elas ultrapassaram os 100 mil barris anuais. Nas décadas de 1720 e 1730, elas atingiram uma média de 140 a 150 mil barris, vindo a superar os 200 mil barris nos anos 1760 , média que se manteve constante até o início da década de 1780 e que marcou o auge das exportações irlandesas. A principal causa do boom ocorrido entre 1710 e 1760, foi a ampliação do setor açucareiro francês. ${ }^{7}$ Entre 1715 e 1730, a população total das Antilhas Francesas e da Guiana duplicou, alcançando 195.073 pessoas (dos quais 160.278 eram negros escravos). Uma geração mais tarde, essa população tinha quase dobrado, chegando, em 1750, a 323.433 pessoas, dos quais 281.658 eram escravos (MANDELBLATT, 2007, p. 36). Nesse contexto, entre 1718 e 1754, as ilhas francesas ultrapassaram as inglesas como principais compradoras das carnes em diversos anos, reunindo algo entre 40\% e 60\% do total das exportações irlandesas. ${ }^{8}$ Em termos de volume, as quantidades importadas pelas antilhas francesas neste período foram de duas a quatro vezes superiores aos montantes negociados nos anos $1680 .{ }^{9}$

Outro fator que favoreceu o desenvolvimento econômico da Irlanda neste período foi a liberdade comercial que os ingleses ofereciam às suas colônias dentro dos portos que pertenciam ao "primeiro Império Britânico". Como demonstrou Truxes, uma vigorosa rede mercantil conectava os comerciantes estabelecidos nos portos ingleses e irlandeses com os das colônias do Caribe e da América do Norte. Em New York, Boston e Philadelphia, por exemplo, verdadeiras comunidades de comerciantes irlandeses, ligados por vínculos parentais e religiosos com outros tantos grupos de mercadores estabelecidos nos outros portos, atuavam fortemente nos negócios transatlânticos. Neste circuito que envolvia o Caribe inglês, as ilhas britânicas e as colônias do norte da América, era muito comum a prática do comércio triangular, como, por exemplo, Boston - Cork - Jamaica - Boston. Das colônias americanas saiam embarcações com madeiras, linhaça e rum para a Irlanda, de onde 
seguiam para as ilhas caribenhas com carnes salgadas e manufaturas, direcionando-se posteriormente para Boston com mais melaço e rum. Além deste comércio, a América do Norte também remetia trigo e farinha diretamente para o caribe inglês. Na segunda metade do XVIII, estas exportações também atingiram Lisboa, Cadiz e outras partes do Mediterrâneo, trazendo no retorno manufaturas europeias (TRUXES, 1988, p. 111-117).

Conforme Mandelblatt, qualquer grande comerciante em atividade no Atlântico daqueles tempos conhecia a fama das carnes irlandesas (MANDELBLATT, 2007). Estudando os negociantes franceses Jean e Pierre Pellet, Fernand Braudel destacou a fortuna adquirida por ambos os irmãos numa rede mercantil constituída na primeira metade do setecentos e que alcançou notável amplitude, envolvendo uma série de comissionistas e "capitães gerentes" de seus navios. Sobre a atuação de Jean, Braudel escreveu:

A quantidade de suas relações de negócios e de seus negócios é simplesmente espantosa: ei-lo armador, negociante, financista em certas ocasiões, proprietário fundiário, produtor e mercador de vinhos, possuidor de rendimentos; ei-lo ligado à Martinica, a São Domingos, a Caracas, a Cádiz, à Biscaia, a Bayonne, a Toulouse, a Marselha, a Nantes, a Rouen, a Dieppe, a Londres, a Amsterdam, a Middelburgo, a Hamburgo, à Irlanda (para comprar carne bovina salgada), à Bretanha (para comprar tecido) e não digo tudo... E naturalmente aos banqueiros de Paris, de Genebra, de Rouen (BRAUDEL, 1996, p. 125-127, grifo nosso).

Passada a época de ouro da carne salgada irlandesa, outros rivais começaram a disputar os mercados consumidores do produto. As colônias inglesas do norte da América sempre foram as maiores concorrentes dos irlandeses e ingressaram no mercado das carnes favorecidas pelos conflitos políticos internos que afetaram a Irlanda após a Revolução Gloriosa (1688-1689). ${ }^{10} \mathrm{Na}$ década de 1720, os irlandeses perderam a posição de maiores abastecedores das antilhas inglesas exatamente para estas colônias (muito embora não tenham 
"Os segredos da carne": o mercado atlântico das carnes secas...

deixado de ser os maiores exportadores de carnes). ${ }^{11}$ Além da pesca, o trunfo destas colônias era a agricultura, destacando-se o cultivo do trigo, do arroz, do milho, entre outros. ${ }^{12}$

Com o desencadear da Revolução Americana, em 1776, a Irlanda começou a perder os privilégios que lhe beneficiavam por fazer parte do sistema comercial no interior do Império Britânico, já que mantinha intensa e lucrativa transação mercantil com os portos da América do Norte. Por mais que os ingleses tentassem impedir, a jovem nação estadonidense expandiu sua rede de abastecimento para todo o Caribe e ampliou as suas exportações de alimentos para a Europa nas décadas que sucederam a Revolução. Conforme Gary Walton, o papel abastecedor das colônias no norte da América já era notável mesmo antes da Independência. Entre os anos 1760 e 1770, elas já exportavam grandes quantias de carnes salgadas (bovina e suína), milho, farinha e trigo para o Caribe e o Sul da Europa (WALTON, 1979, p. 81-82; 193). Além disso, a Revolução em Santo Domingo interrompeu momentaneamente o mercado caribenho francês trazendo prejuízos aos comerciantes e provocando uma queda nas exportações de carne salgada irlandesa (MANDELBLATT, 2007, p. 20). Em 1800, a união dos Reinos da Irlanda e da Grã-Bretanha colocou os primeiros sob a hegemonia do Parlamento inglês, restringindo parte da sua autonomia política e econômica. No início do século XIX, a Irlanda continuou exportando carne salgada, mas jamais recuperou os índices setecentistas. Em 1815, por exemplo, as remessas do produto eram quatro vezes inferiores ao que havia sido negociado na década de 1770, e em 1840, os números não chegavam a 3\% do que o país havia exportado nos anos 1780 (IOMAIRE; GALLAGHER, 2011). A decadência econômica da pequena ilha foi marcada pela Grande Fome (1845-1849) que ceifou cerca de 1,5 milhões de vidas. Apesar disso, o "legado" irlandês no interior do sistema mercantil atlântico havia fincado raízes... 


\section{Os mistérios das carnes: especialistas e estrangeiros nas primeiras fábricas do extremo sul da América}

Conforme Mandelblatt, as fábricas irlandesas combinavam especialização da mão de obra, baixos salários e técnicas avançadas de processamento, permitindo a mais eficiente produção de carnes de sua época. Observador perspicaz, o ministro Colbert tentou imitar o sucesso dos fabricantes irlandeses patrocinando a formação de um complexo fabril de carne salgada na própria França. No entanto, devido às guerras, aos grandes custos de produção, aos tributos sobre o sal e à concorrência irlandesa, Colbert deu-se por vencido e abriu de vez o comércio dos portos franceses às carnes irlandesas (MANDELBLATT, 2007, p. 25-30). O resultado disto foi que os irlandeses não legaram apenas um modelo fabril e mercantil das carnes para o mundo atlântico, como também deixaram um exemplo de que era possível obter grandes lucros alimentando escravos e marinheiros. As muitas décadas de exportação de sal para a Irlanda e importação de carne salgada para abastecer as suas tripulações marítimas aproximou bastante os comerciantes portugueses e espanhóis do circuíto mercantil intra-europeu do qual os irlandeses faziam parte. ${ }^{13}$ Os comerciantes ibero-americanos nunca estiveram indiferentes às rotas atlânticas das carnes. Portanto, durante o colonial tardio, foi comum comerciantes e proprietários luso-brasileiros e hispano-platinos interessados nos negócios com as carnes fazerem referência aos irlandeses.

Como foi dito, o modelo de fabricação irlandês constituia-se em preparar as carnes e conservá-las salgadas em barris de madeira com salmoura. ${ }^{14}$ Nesta época, este tipo de carne era o produto preferido para o abastecimento das tripulações navais. Neste sentido, as Coroas ibéricas, que importavam as mesmas dos irlandeses, pareciam incentivar mais a sua manufatura do que a do charque. Sabedores desta preferência, tanto os comerciantes espanhóis e portugueses, quanto os ibero-americanos, começaram a propor o abastecimento das Armadas ibéricas com este tipo de carne. Em 1789, por exemplo, três comerciantes portugueses requisitaram ao Conselho Ultramarino enviar para o Rio Grande do Sul seus navios com "o sal necessário para a salga das carnes e dos couros", argumentando que

Anos 90, Porto Alegre, v. 24, n. 45, p. 153-182, jul. 2017 
"Os segredos da carne": o mercado atlântico das carnes secas...

o território era muito próprio para "fazer carnes de moura para o serviço da Marinha, à imitação das da Irlanda, e tirar o sebo apurado e necessário a usos domésticos". No entanto, suas propostas eram ainda mais ousadas e previam remeter para o Rio Grande escravos da Costa da África e Moçambique e réus condenados que tivessem como ofício a tanoaria e a carpintaria (para serem empregados nas fábricas na manufatura dos barris), estimular a criação de carneiros (para a produção da lã) e porcos (para a fabricação de toucinho), plantar pinhos e carvalhos, "a exemplo do que fizeram os ingleses em Filadélfia e Nova York”, e instalar uma fábrica de solas, para aproveitar os couros das charqueadas, além de outros planos. ${ }^{15}$

Com exceção da entrada de cativos africanos para o Rio Grande do Sul, os demais objetivos não vingaram. A produção de carnes salgadas em barris nesta capitania, embora tenha rendido seus lucros para alguns fabricantes, nunca atingiu índices semelhantes aos das exportação de charque. Nos primeiros anos de funcionamento das charqueadas muitas vezes as autoridades lusitanas reclamavam da qualidade da carne em barris produzida no Rio Grande do Sul. Em setembro de 1789, por exemplo, alguns comerciantes reinóis disseram que as carnes salgadas trazidas do Rio Grande por Manoel Pinto da Silva não estavam em perfeito estado e que, em Lisboa, ninguém as queria comprar. Os mesmos acrescentavam que o problema não era a qualidade das carnes, mas sim os métodos usados pelos fabricantes. ${ }^{16}$ Anos mais tarde, o capitão de um outro navio ordenou que a tripulação jogasse uma carga inteira de carne salgada em alto mar por ela haver se deteriorado na viagem. ${ }^{17}$ No início do século XIX, o Governador da Capitania ainda se ressentia do pouco sucesso das carnes em barris e o Vice-Rei Conde de Resende compartilhou com ele os mesmos anseios:

É certo que a primeira amostra da tentativa que se fez das carnes salgadas não correspondeu aos bons desejos que tanto eu como V. Ex. ${ }^{a}$ teríamos de ver o feliz êxito de tão eficazes diligências [...], mas além do que com o tempo e com trabalho que promete para o futuro grandes lucros é que se [aperfeiçoe] semelhantes fábricas. Penso que a assistência desses homens que vieram do Reino para instruírem sobre 
o modo de fazer as salgas, ter-se-á adquirido outro melhor conhecimento e mais seguro método; e por [consequência], pôr em giro o comércio das carnes, ainda que por ora, se aplique toda a que se puder beneficiar para o consumo da Esquadra, enquanto aquele não tem maior extensão. ${ }^{18}$

Observe-se que o Conde de Resende não apenas tinha esperanças de abastecer a Marinha lusitana, como também colocar no mercado o excedente das carnes salgadas produzidas no Rio Grande. Para que os negócios deslanchassem, os administradores entendiam que era necessário a presença de fabricantes mais instruídos naquele ramo, pois a sua ausência vinha sendo prejudicial aos mesmos. A participação de experts na fabricação das carnes era encarada como algo fundamental para o sucesso tanto nas charqueadas pelotenses, como entre os saladeros platinos do período. No entanto, quem seriam estes experts? Numa outra missiva remetida pelos comerciantes portugueses mencionados anteriormente, os mesmos se obrigavam a: "fazer as carnes de moura à imitação da Irlanda, o que é facílimo assim que haja Mestre, e ainda sem ele, haverá portugueses que a tem feito no ardente clima da Nossa América, e que vão a India e voltam à Lisboa". ${ }^{9}$

De fato, já existiam portugueses fabricando pequenas quantias de carnes em barris no próprio Rio Grande do Sul e, igualmente, na Ilha de Marajó (ao norte do Grão Pará). ${ }^{20}$ Mas o mais interessante, conforme o trecho grifado acima, é que estes especialistas portugueses pareciam ser a segunda opção diante dos indivíduos desejáveis para ocupar a função de "mestre" de salga. Os experts com maior reputação neste ramo de negócios eram os irlandeses e os ingleses. Em agosto de 1801, o Visconde de Anadia recebeu um ofício relatando que o comerciante João Rodrigues Pereira de Almeida enviara para Lisboa uma segunda amostra de carnes em barris " $\mathrm{O}$ qual encarregou da dita salga, a dois irlandeses que daqui mandou ir", com o objetivo de prover o Arsenal Real da Marinha. ${ }^{21}$ Pereira de Almeida, que era um dos mais ricos comerciantes de grosso trato do Rio de Janeiro, havia construído uma fábrica de salgar carnes no Rio Grande do Sul. Anos antes, ele socilitou instrumentos de trabalho para os irlandeses João Seechy (mestre), Pedro O’Donnel (salgador) e Diogo Sheehy (curtidor) (GUTIERREZ, 2001, p. 121). 
"Os segredos da carne": o mercado atlântico das carnes secas...

Em 1805, Pereira de Almeida, oferecendo-se para abastecer a Marinha lusa, propôs um contrato de fornecimento de barris de carne, "cuja salga é feita por mestres irlandeses que ali tem, e como a de Irlanda da melhor qualidade". Nesta ocasião, Pereira de Almeida recebeu parecer negativo, pois o período de 9 anos de contrato foi considerado muito arriscado. Os funcionários da Coroa argumentaram que era possível conseguir carne irlandesa de melhor qualidade por um preço inferior. Nesta época, conforme os mesmos, além da Irlanda, Portugal também recebia carnes salgadas da "América" e da Dinamarca. ${ }^{22}$ Em 1808, Pereira de Almeida ainda possuía a sua fábrica de carnes na capitania sul-rio-grandense. Conforme o relato de um contemporâneo sobre o seu "grande e interessante estabelecimento", ele possuía "grandes ordenados e despesas", pois mandara "vir a sua custa mestres da Irlanda" (MAGALHÃES, 1980, p. 88).

Tal exigência não se tratava de uma singularidade luso-brasileira. Entre os hispano-platinos, a escolha de mestres irlandeses e ingleses para operacionalizarem a produção das carnes salgadas nos primeiros anos também foi marcante. Além do conhecimento técnico que possuíam, a preferência da Marinha européia pelas carnes irlandesas os credenciavam para esta atividade. O saladeirista Francisco de Medina teria sido o primeiro a conseguir realizar tais técnicas com perfeição, "[...] através da instalação de um laboratório montado no estabelecimento, dirigido por técnicos irlandeses" (MONQUELAT, 2012, p. 80). O desafio em acertar o ponto correto do preparo das carnes, seu sabor e a resistência à deterioração era tão difícil que o Vice-Rei Nicolás de Arredondo comemorou com entusiasmo tal feito, revelando que os especialistas haviam descoberto o "segredo". ${ }^{23} \mathrm{O}$ ânimo deve ter tomado conta de muita gente e a notícia se espalhado rapidamente. Em 1794, entre as medidas aconselhadas pelos estancieiros e fabricantes de Buenos Aires e Montevidéu a um ministro espanhol para que a indústria saladeril obtivesse êxito, estavam, primeiramente, "hacer venir de Irlanda de 80 a 100 maestros en salar carnes" e "fundar una Compañía Marítima que tuviera a su cargo el transporte de los barriles a la península” (MONTOYA, 1956, p. 29-30).

Contudo, na fase inicial desta indústria, além da mão de obra e da orientação técnica qualificada também havia outros problemas. 
Conforme Aníbal Pintos, a ausência de toneleros constituía-se num obstáculo para a ampliação dos negócios. No fim do século XVIII, só existiam 8 destes especialistas em Montevidéu e os mesmos não davam conta da demanda por barris. A solução, segundo o autor, foi agregar com frequência cerca de 5 ou 6 ingleses que haviam chegado no Prata para caçar baleias e que conheciam as técnicas irlandesas (PINTOS, 1973, p. 150). Quando não era possível trazer irlandeses ou ingleses, os investidores menos exigentes aceitavam os ibéricos, desde que fossem talentosos nesta atividade. Em 1778, por exemplo, o projeto de implantação de uma fábrica de carnes salgadas enviado à Coroa espanhola pelo Cabildo de Buenos Aires solicitava que viessem da Espanha vários toneleros e quatro sujeitos inteligentes que conhecessem das carnes salgadas (MONTOYA, 1956). Portanto, o know-how trazido por estes indivíduos foi de extrema importância no início desta fase empresarial. Nos anos 1780, por exemplo, Miguel Ryan, espanhol de ascendência irlandesa, instalou-se na Banda Oriental trazendo antiga experiência com salga de carnes no Chile (MONQUELAT, 2010b).

Portanto, desde os primeiros anos de funcionamento dos saladeros no Rio da Prata, os ingleses e irlandeses estiveram presentes tanto entre os experts do setor produtivo, quanto nos setores mais subalternos das fábricas. E, igualmente, desde os anos 1780, os saladeros exportaram quantidades significativas de carnes em barris. ${ }^{24}$ Em 1781, Manuel Melian, um dos primeiros empresários a instalar-se no Prata, remeteu para Cadiz cerca de 136 barris em dois navios. Em 1785, o catalão Juan Ros remeteu 202 barris do produto para Cuba (PINTOS, 1973, p. 147-148).

Outros seguiram o mesmo exemplo e Montevidéu continuou atraindo comerciantes e investidores nos anos 1780. Da primeira geração de saladeiristas orientais destacaram-se o mencionado Francisco de Medina e também Francisco Maciel. O primeiro deles teria fundado seu estabelecimento em 1780, mantendo uma produção anual de 8 mil quintais de carne salgada (cerca de 360 toneladas) (CASTELLANOS, 1871, p. 31). Quando faleceu, Medina possuía um grande patrimônio, onde se destacavam uma estância com 25 mil cabeças de gado e 6 embarcações empregadas tanto no carregamento de sal, quanto na exportação de carnes e couros para 
"Os segredos da carne": o mercado atlântico das carnes secas...

a Europa (MONTOYA, 1956, p. 25). Em 1788, Maciel (que era assentista de víveres da Real Armada em Montevidéu), estabeleceu uma fábrica de carnes salgadas, tasajo e sebo, tornando-se um dos mais ricos saladeiristas da região. O sucesso de ambos motivou o estabelecimento de outros empresários. Juan Camilo Trápani, Juan Balvín y Vallejo e Don Miguel Ryan tiveram matadouro em Arroio Seco. Manuel Solsona e Luiz Antonio Gutierrez também se estabeleceram nesta década. Em 1790, Nicolás Lacort instalou-se nas imediações de Montevidéu. Em 1791, foi a vez de Esteban Durán e Fernando Martínez; em 1793, Juan Ignacio Martínez, cujo mestre de salga era Tadeo González; em 1797, em La Estanzuela, o de Juan Jose Seco; em 1798, o de Salvador Tort, na Ponta das Carretas, entre outros (PINTOS, 1973). Em 1801 havia cerca de 30 saladeros na parte oriental do Rio da Prata, abatendo anualmente 120 mil reses e empregando mais de 1.000 homens - livres e escravos - em suas fábricas (MONTOYA, 1956, p. 31).

Contudo, ao contrário de Montevidéu, a região de Buenos Aires teve seus primeiros saladeros somente a partir da década de 1810 (MONTOYA, 1956, p. 31). Uma das explicações para este investimento tardio pode ser dada pelo fato de que os comerciantes portenhos lucravam muito com as exportações de couro e prata, os desviando de um maior interesse em investir seus capitais em fábricas de carne salgada. A independência do Vice-Reinado do Rio da Prata e a consequente ruptura das rotas mercantis terrestres com os territórios que viriam a ser a Bolívia e o Peru, cessaram o fluxo de metais para a região, possibilitando o crescimento das inversões na pecuária e nas fábricas de carne (SOCOLOW, 1975; ROSAL; SCHMIT, 1999). Além disso, o Movimento de maio de 1810 e a Junta governativa que lhe sucedeu favoreceram a indústria com uma série de medidas. Um grupo de comerciantes e estancieiros que acompanhou o processo de Independência logrou franquias mercantis e tornou-se líder nos negócios com a carne buenairense. Entre eles estava Juan Manuel de Rosas, que viria a ser governador da Província de Buenos Aires. Conforme Horacio Giberti, Rosas não encontrou dificuldades para reunir outros sócios capitalistas e formar a Rosas, Terrero y Cia., cujo primeiro saladero começou a funcionar em 1815. A influência que exercia em setores governamentais 
estratégicos e seus laços de parentesco o favoreceram bastante neste ramo de atividades (GIBERTI, 1981).

Além de Rosas e Dorrego, entre os primeiros saladeiristas instalados naquelas terras estavam os ingleses R. Staples e J. Mac Neil, que ergueram sua fábrica no ano de 1812. Investindo um grande montante de capital, eles possuíam 60 trabalhadores assalariados, sendo 8 toneleros, 2 carpinteiros e 4 peões trazidos especialmente da Europa. Quase que instantaneamente ao advento desta fábrica, muitos outros montaram seus saladeros na região, chegando a 14 estabelecimentos estreitamente vinculados à firma de Rosas, que liderava os empreendimentos regionais (GIBERTI, 1981, p. 84-85). Anos depois, seu número aumentou. Segundo Montoya, entre 1822 e 1825, existiam 20 saladeros ao redor de Buenos Aires (MONTOYA, 1956, p. 39). Somados aos saladeiristas de Montevidéu, percebe-se que além dos hispano-platinos, que formavam a maioria, alguns deles vinham da Espanha e que outra parte significativa era formada por indivíduos com sobrenomes ingleses e franceses. Anibal Pintos faz referência a vários deles: Stanley Black \& Cia, Tomas Tomkinson, Henrique Jones, Pablo Duplessis, Buther \& Martin, Juan Jackson, Hipólito Doinnel, Juan Hall e o Sr. Young, entre outros (PINTOS, 1971). Isto revela que quando não vinham para trabalhar como mestres, tanoeiros ou assalariados, os imigrantes europeus arriscavam-se a montar uma fábrica nas margens do Prata, com capitais parcialmente reunidos no exterior.

Pelotas, por sua vez, possuía um perfil de investidores um tanto distinto. Embora o número de charqueadas fosse aproximado ao de ambas as localidades platinas (em 1822 havia 18 charqueadas e, em1833, havia pouco mais de 30 estabelecimentos), a presença de investidores ingleses e franceses era praticamente inexistente. De 62 charqueadores que tiveram seus estabelecimentos em Pelotas entre 1790 e 1835, localizei a naturalidade para 48 deles: 23 eram nascidos na América lusa, 22 no Reino e nas Ilhas, 2 na Colônia de Sacramento e 1 na Espanha. Embora o porto de Rio Grande fosse bastante frequentado por comerciantes europeus e norte-americanos, a vizinha Pelotas (principal núcleo charqueador do sul do Brasil) pareceu estar fechada aos investidores anglo-franceses. Isto não significa que alguns não tenham tentado. Certamente o caso mais 
"Os segredos da carne": o mercado atlântico das carnes secas...

ilustrativo envolve o francês Jean Baptista Roux - provavelmente um dos pioneiros em empregar mão de obra assalariada nas charqueadas pelotenses. Instalando-se primeiramente em Triunfo, Roux passou por Porto Alegre, Rio Pardo e Rio Grande até que, em 1846, arrendou a charqueada do Visconde de Jaguari, em Pelotas. Neste estabelecimento, ele empregou trabalhadores de diferentes nacionalidades juntamente com 30 escravos alugados, num empreendimento que, em sociedade com Eugène Salgues, durou pouco mais de cinco anos. (VARGAS, 2013, p. 101-102; 123-124).

Os saladeros platinos fabricavam tanto o charque (tasajo) quando a carne salgada. Contudo, os dados sobre exportação nem sempre separavam ambos os produtos, contabilizando-os somente como carnes salgadas, quando se sabe que grandes remessas de tasajo eram realizadas nesta época (GARAVAGLIA, 1994; ROSAL e SCHMIT, 1999). Mas a partir de dados coletados por Montoya, sabe-se que em 1798, 1799 e 1800, Montevidéu exportou 24.100, 16.254 e 27.794 barris de carne, respectivamente (MONTOYA, 1956). Trata-se de um alto índice de remessas para uma indústria em sua fase inicial. O Rio Grande do Sul, por exemplo, não chegou nem perto disso. Nos 16 anos entre 1805 a 1820, a capitania sulina exportou 43.499 barris de carne, ou seja, uma média de 2.718 por ano - bem menos que as exportações orientais no final do século XVIII (CHAVES, 1978, p. 116-118; 134-141). Em 1808, Antônio de Magalhães disse que existiam somente duas fábricas no Rio Grande que fabricavam barris de carne salgada, exportando 3 mil deles por ano (MAGALHÃES, 1980, p. 88).

A pouca representatividade do Rio Grande do Sul nos investimentos em carnes em barris pode ser explicada por dois motivos. Primeiramente, os proprietários e os trabalhadores ingleses e irlandeses, especialistas ou não, parecem ter tido pouquíssima presença nas charqueadas de Pelotas. Não é possível saber se esta relativa ausência foi fruto de seu desinteresse pela região, se era consequência de uma política luso-brasileira mais restritiva antes da abertura dos portos (1808) se comparada ao Rio da Prata ou se os próprios charqueadores pelotenses criavam obstáculos para não tê-los como concorrentes em seu próprio quintal. $\mathrm{O}$ fato é que a sua significativa presença nos saladeros platinos favoreceu a maior envergadura de 
investimentos que aqueles países conheceram ao longo do oitocentos. Como as carnes em barris tinham nas tripulações dos navios uma importante consumidora, não deve ser desprezado o fato de que as Marinhas inglesas e francesas possuíam um perfil muito mais internacionalizado do que a portuguesa. Conforme Jaime Rodrigues, a única internacionalização que caracterizou a Marinha lusa foi a presença de africanos entre os seus marinheiros, ao contrário da francesa e da inglesa que possuíam marinheiros europeus de diversas procedências (RODRIGUES, 2015). Se pensarmos que a presença de franceses e ingleses entre os fabricantes de Montevidéu e Buenos Aires foi muito mais expressiva do que em Pelotas, podemos supor que as redes mercantis nas quais os mesmos estavam inseridos apresentavam uma demanda muito maior pelas carnes em barris - alimento tradicionalmente consumido entre as tripulações navais do Atlântico norte.

Contudo, outra questão talvez ajude a explicar parte dos motivos pelo qual os charqueadores pelotenses não investiram nas carnes em barris. Eles estavam inseridos principalmente em redes mercantis luso-brasileiras, que facilitavam os seus negócios com regiões de antigo consumo de carne-seca, como os escravos do norte açucareiro, por exemplo. O charque possuía dentro da própria América portuguesa um vigoroso e promissor mercado consumidor, pronto a gerar bons lucros. Neste sentido, é importante mencionar que um dos responsáveis por levar o charque pelotense para o mercado baiano e pernambucano foi justamente um comerciante que fabricava charque no Ceará e que, após as duras secas que afetaram a Capitania em 1791, migrou para Pelotas de vez, tornando-se charqueador nessa região (VARGAS, 2013, p. 106-113).

Além disso, conforme Sluyter, o charque tinha algumas vantagens sobre as carnes em barris. Sua prepação era mais simples, ele ocupava bem menos espaço nos navios e podia ser colocado em qualquer canto dos porões, ou seja, ele favorecia fabricantes com menos capitais para investir em melhorias técnicas. Soma-se a isso o fato de que o charque comprado para alimentar as escravarias das plantations não passava por uma rigorosa vistoria, como as carnes salgadas remetidas para as Armadas. ${ }^{25}$ Portanto, acredito que as poucas quantidades de carnes em barris exportadas pelo Rio Grande 
"Os segredos da carne": o mercado atlântico das carnes secas...

do Sul também foram resultado de uma escolha dos comerciantes envolvidos em uma rede mercantil cujo objetivo era abastecer a escravaria das plantations (com uma mercadoria de qualidade inferior) e não as Armadas europeias (algo que fugia, em parte, dos planos da Coroa lusa). Neste sentido, apesar das dificuldades em acertar o "ponto" das carnes em barris, as poucas remessas rio-grandenses não se tratavam apenas da sua incapacidade técnica. Nas palavras de um próprio charqueador de Pelotas, escritas entre 1817 e 1822, isto fica claro: "a carne salgada em barris é, sim, toda ela fabricada em Porto Alegre: no Rio Grande [o que incluía Pelotas] não se fabrica carne em barris, ainda que se podia fabricar quanta se quisesse" (CHAVES, 1978, p. 141). Talvez Gonçalves Chaves estivesse sendo otimista demais no que diz respeito à possibilidade de se "fabricar quanta [carne] se quisesse". O tímido sucesso dos fabricantes de carnes em barris instalados em Porto Alegre demonstra as fragilidades do setor na localidade e a pouca competitividade do produto se comparado ao charque pelotense e aos concorrentes platinos.

O fato é que a produção de carne em barris era mais para suprir uma demanda estimulada pelo Reino, que queria substituir as compras das carnes irlandesas para a Marinha lusitana, do que um investimento destinado a outros mercados consumidores. ${ }^{26}$ Neste sentido, acredito que não era comum pensar nas carnes em barris para alimentar os escravos das plantations luso-brasileiras, por exemplo. Além disso, a produção das carnes salgadas também era estimulada por autoridades estrangeiras que mantinham contato com os burocratas portugueses. Nos anos 1790, Donald Campbell, oficial britânico encarregado do comando de uma Esquadra na América, recomendou à Armada portuguesa que empregasse outros métodos para salgar as suas carnes, pois utilizando meios muito primitivos, elas não estavam sendo satisfatórias no abastecimento da tripulação lusa (XAVIER, 1974, p. 9). É provável que Campbell preferisse as carnes em barris ao invés das mantas de charque. Esta também foi a queixa do Governador do Grão-Pará, quando buscou estimular a fabricação de carnes em barris na Ilha de Marajó, pois, na opinião dele, estas eram muito mais higiênicas e saborosas do que as carnes secas que lá se fabricavam e que colocavam em risco a saúde da população consumidora. ${ }^{27}$ Soma-se a isso o fato de que, entre os 
ingleses, o charque era considerado comida de escravos (VARGAS, 2014). Portanto, nos diferentes "projetos" relativos à fabricação de carnes no Rio Grande do Sul, a matriz "nativa" (charque) acabou vencendo a matriz irlandesa (carne salgada em barris).

No Império espanhol aconteceu algo semelhante. Apesar da significativa produção de tabaco e açúcar em Cuba, suas plantations, no meado do setecentos, eram bastante prejudicadas pelo alto preço dos escravos importados e pela restrição dos mercados, visto que a Espanha não tinha acesso direto ao tráfico atlântico e restringia bastante o comércio de sua colônia caribenha. Na década de 1780, Cuba possuía "uma classe de aspirantes a proprietários de plantations ansiosa para imitar o sucesso das colônias açucareiras das outras potências. Tudo o que precisava era acesso fácil aos escravos e aos mercados". Em 1787, a livre entrada de escravos foi permitida pela primeira vez e com a Revolta em Santo Domingo, a ilha espanhola importou milhares de cativos e multiplicou a sua produção açucareira. Se em 1787 as exportações atingiram 10 mil toneladas (o dobro da quantidade exportada em 1760), em 1802 este índice saltou para 40 mil toneladas. $\mathrm{Na}$ virada do século, mais de mil navios de diversas bandeiras iam anualmente a Cuba. As autoridades coloniais "deram toda ajuda à expansão das plantations, ignorando, quando necessário, a legislação ou as instruções da metrópole". Comerciantes coloniais, atuando em parceria com norte-americanos, fretavam inúmeras embarcações. Se antes de 1789, Cuba teria importado 100 mil escravos, entre 1790 e 1821, este número aumentou para 240 mil cativos africanos (BLACKBURN, 2003, p. 602-604).

$\mathrm{O}$ aumento das exportações de Montevidéu e Buenos Aires também foi estimulado por uma série de medidas políticas tomadas pelos Bourbons. Em 1776, a Coroa decretou o livre comércio dos portos espanhóis com Buenos Aires, substituindo o exclusivismo de Cadiz. Em 1777, foi criado o Vice-Reinado do Rio da Prata, oferecendo uma maior autonomia administrativa à região. Como resultado destas medidas, o comércio portenho dinamizou-se e uma poderosa classe de negociantes marítimos constituiu-se a partir destas trocas. ${ }^{28}$ Entretanto, conforme Montoya, o objetivo inicial dos saladeiristas não era fabricar o tasajo. Por atenderem os anseios vindos de Madrid, muitos deles queriam produzir as carnes irlandesas

Anos 90, Porto Alegre, v. 24, n. 45, p. 153-182, jul. 2017 
"Os segredos da carne": o mercado atlântico das carnes secas...

para a Marinha espanhola (MONTOYA, 1956). No entanto, diante do boom açucareiro em Cuba e do crescimento daquele mercado provocado pela entrada de milhares de escravos, a ampliação da fabricação do tasajo foi tentadora e a carne salgada foi lentamente sendo substituída por este, cujas remessas se multiplicaram ao longo do oitocentos (SLUYTER, 2010).

Portanto, a indústria das carnes preparadas teve um impressionante impulso com a crescente montagem de plantations açucareiras escravistas que marcou o período colonial tardio. Com vistas a obter maiores lucros no comércio do produto, negociantes de distintas regiões do atlântico instalaram-se no cone sul americano, promovendo o surgimento de dezenas de fábricas, atraindo investidores, estimulando o tráfico atlântico de escravos para a região, a migração de trabalhadores livres, a expansão da fronteira agrária combinada com a pecuária extensiva, contribuindo, assim, com a dinâmica interna do sistema mercantil atlântico que caracterizou o período. Tais fenômenos provocaram uma profunda transformação nas paisagens agrárias rio-grandenses e platinas, cujos efeitos econômicos, políticos e culturais marcaram a história das suas respectivas sociedades.

\section{Conclusão}

Tanto a fabricação e o comércio do charque, quanto das carnes em barris, pareciam ser bastante lucrativos. Contudo, o tipo de carne preparada dependia muito dos interesses e das possibilidades dos fabricantes, da rede mercantil em que os mesmos estavam inseridos, dos estímulos governamentais, das conjunturas econômicas e da qualidade da demanda. Em última instância foi um empreendimento cada vez mais liderado por particulares que expressavam as capacidades de inversão das elites coloniais neste ramo de negócios, em detrimento da vontade das Coroas Ibéricas. Um dos motivos pelo qual a produção de carnes salgadas em barris vingou mais entre os platinos do que entre os rio-grandenses (além do suposto pouco interesse dos charqueadores pelotenses em fábricar tais produtos) foi a notável presença de técnicos irlandeses e ingleses entre os saladeros

Anos 90, Porto Alegre, v. 24, n. 45, p. 153-182, jul. 2017 
e a influência e conhecimento que os mesmos detinham no que diz respeito a este produto. Além do mais, a população caribenha estava mais adaptada ao consumo das carnes em barris (por herança das carnes irlandesas) do que a América portuguesa - que já vinha, em parte, sendo abastecida pela carne-seca do Ceará e do Piauí (e cujas técnicas de fabricação já eram conhecidas pelos colonos e indígenas mesmo antes do setecentos).

Os ingleses e irlandeses estiveram presentes na indústria das carnes platinas desde a sua fundação. Todo este intercâmbio de homens e ideias foi favorecido pela conjuntura política e econômica que marcou o Império espanhol durante o governo dos Bourbons e que também encontrou certo fomento metropolitano com as medidas pombalinas lusas realizadas um pouco antes do período aqui trabalhado (SCHWARTZ, 1999; VARGAS, 2013). Contudo, nesta fase inicial, a presença de ingleses, franceses e irlandeses em Pelotas foi praticamente inexpressiva. Tal fenômeno não significa que Pelotas estivesse isolada de tais trocas culturais e econômicas. Muitos dos charqueadores e comerciantes estabelecidos naquela região eram reinóis e, como foi visto, o sucesso dos irlandeses neste ramo de negócios era conhecido em todo o Atlântico. Além dos mais, esta interação social não deixou de envolver o contato direto dos luso-brasileiros com os portos platinos e vice-versa. Eis aqui algo que ainda precisa ser mais bem estudado. Pesquisas mais recentes demonstram que mesmo concorrendo pelos mesmos mercados, estes agentes trocavam experiências sobre o ramo de negócios, estando imersos em distintas redes de relações imperiais e trans-imperiais que envolviam negociantes, burocratas, traficantes, saladeiristas e charqueadores (PRADO, 2009; KUHN, 2012; VARGAS, 2013). Mas isto já é uma outra história... 
"Os segredos da carne": o mercado atlântico das carnes secas...

\section{"MEAT SECRETS": THE ATLANTIC MARKET FOR DRIED AND SALTED BEEF AND THE INFLUENCE OF IRISH MANUFACTURING METHODS ON THE SOUTHERN LATIN AMERICA (C. 1780 - C. 1820)}

Abstract: In the late colonial period, Pelotas (in Rio Grande do Sul), Buenos Aires and Montevideo were central economic nodes of dried meat industries, supplying the growing demand for food. Before this regional development, Ireland had considerable importance in the manufacture and trade of salted meats in the Atlantic, even though using distinct techniques. This paper demonstrates the conflict between Irish and native methods in the preparation of this important product, by analyzing the circulation of Irish men in this macro-region and the trajectories of investors in this important business.

Keywords: Jerked beef. Atlantic trade. Slavery. Rio da Prata.

\section{Notas}

${ }^{1}$ As informações são fruto de um projeto coletivo que teve como principais coordenadores David Eltis e David Richardson. A página foi recentemente traduzida por pesquisadores da Casa de Rui Barbosa e está disponível no site da mesma instituição: http://slavevoyages.org/ (último acesso em 30 de agosto de 2016). ${ }^{2}$ A bibliografia sobre esta conjuntura econômica atlântica é vasta. Para algumas sínteses ver BLACKBURN (2003), SCHWARTZ (1999), HOBSBAWM (2009), BORUCKI; ELTIS; WHEAT (2016). Para a região estudada no presente artigo, ver BRADING (1990), ALDEN (1990), OSÓRIO (2007), MENZ (2009), PRADO (2009), VARGAS (2013).

${ }^{3}$ Sobre a importância do tráfico de escravos para o Rio da Prata ver BORUCKI (2016), KÜHN (2012), ALADREN (2012). Para o caso de Pelotas ver VARGAS (2013).

${ }^{4}$ Para uma análise dessa conjuntura e sobre os espaços produtores de carnes na América lusa, ver MARQUES (1987), OSÓRIO (2007), ROLIM (2012) e VARGAS (2013).

${ }^{5}$ É o que defendo em VARGAS (2013, capítulos 1, 2 e 3). Para uma análise do mencionado contexto, ver MALERBA (2006), PRADO (2009), LINEBAUGH; REDIKER (2008), MARQUESE (2004), PIMENTA (2002), CHIARAMONTE (2011), RINKE; SCHULZE (2010).

${ }^{6}$ Conforme Robin Blackburn, a "explosão" do comércio colonial foi possibilitada por um crescimento anterior das importações de escravos pelas ilhas inglesas. Este incremento totalizou 263.000 escravos negociados, cuja metade foi remetida

Anos 90, Porto Alegre, v. 24, n. 45, p. 153-182, jul. 2017 
para Barbados, secundada pela Jamaica e as Ilhas Leeward. "A população negra das Índias Ocidentais inglesas cresceu de 42\% do total em 1660 para 81\% em 1700" (BLACKBURN, 2003, p. 325).

${ }^{7}$ Dentre as ilhas caribenhas francesas, Santo Domingo superava Guadalupe e Martinica como a principal consumidora das carnes irlandesas. No seu auge, entre 1763 e 1791, a "pérola das Antilhas" produziu mais lucros do que qualquer outra colônia caribenha, tornando-se a maior produtora de açúcar do mundo. Com uma enorme população escrava, Santo Domingo possuía um habitante branco para cada dez negros em seu território (MANDELBLATT, 2007, p. 22). ${ }^{8}$ Além dos navios mercantis, que negociavam escravos, gêneros alimentícios, tabaco, açúcar e uma série de outras mercadorias, a frota militar também se ampliou de forma notável. Na França, quando Colbert foi indicado para supervisionar as colônias, a França possuía somente duas dezenas de embarcações em alto-mar. Mas em 1683, a Marinha de Guerra francesa já contava com 117 navios de linha, 30 galeões e 80 fragatas corsárias, totalizando 1.200 oficiais e 53.000 marinheiros (BLACKBURN, 2003, p. 354). Ou seja, um notável aumento de potenciais consumidores de carne em barris.

${ }^{9}$ Em 1685, Luís XIV decretou um código especial visando regulamentar a escravidão nas colônias francesas. O Code Noir, como ficou conhecido, mandava que cada escravo recebesse, além de 1,2 Kg de mandioca, cerca de 900 gramas de carne salgada ou $1,4 \mathrm{Kg}$ de peixe salgado por semana, o que também contribuiu para a manutenção das importações de carne salgada (BLACKBURN, 2003, p. 251-253; MANDELBLATT, 2007, p. 29)

${ }^{10}$ Nesta época, Pensilvânia, New York, Virgínia e Maryland passaram a exportar suas carnes para o Caribe, quebrando assim o monopólio prático dos irlandeses (TRUXES, 1988, p. 26-7).

${ }^{11}$ No meado do século XVIII, estas colônias também começaram a exportar significativas quantias de peixe salgado para Santo Domingo. No entanto, este mercado jogava com as oscilações e aberturas da política colonial francesa, sem abrir mão do contínuo contrabando. Santo Domingo importava peixe salgado, legumes e grãos americanos, exportando rum, melaço e outros produtos tropicais (TREUDLEY, 1916, p. 83-145).

${ }^{12}$ Conforme o mesmo autor, "a produtividade agrícola dos fazendeiros e pescadores do Norte era tal que as colônias de plantation das Índias Ocidentais, britânicas ou não, tinham neles seus fornecedores mais baratos" (BLACKBURN, 2003, p. 559-563). ${ }^{13}$ Ver, por exemplo, os destinos das exportações de carnes irlandesas ao longo do século XVIII. Por diversos anos, Espanha e Portugal foram a terceira maior compradora atrás do Caribe inglês e francês, que somados sempre ocupavam mais da metade das remessas (TRUXES, 1988, p. 262-263). 
${ }^{14}$ Segundo Alfredo Montoya, as carnes cortadas permaneciam numa tina com salmoura por cerca de um mês, para depois serem colocadas em barris com camadas alternadas de sal (MONTOYA, 1956, p. 25-26). Segundo Anibal Barrios Pintos, no Uruguai, cada barril suportava 4 arrobas (cerca de $60 \mathrm{~kg}$ ) de carne (PINTOS, 1973 , p. 148). Mandelblatt, por sua vez, considerou que cada barril, na Irlanda do século XVIII, carregava cerca de $90 \mathrm{~kg}$ (MANDELBLATT, 2007, p. 20). ${ }^{15}$ Requerimento de 30.09.1789, Arquivo Histórico Ultramarino (AHU-ACL-CU-019), Cx. 3, Doc. 237 e 238 (Projeto Resgate).

${ }^{16}$ Requerimento de 30.09.1789, AHU-ACL-CU-019, Cx. 3, Doc. 237 (Projeto Resgate).

${ }^{17}$ Carta do Conde de Resende para o Governador da Capitania do RS (20.11.1800) apud MONQUELAT (2010).

${ }^{18}$ Carta do Conde de Resende para o Governador da Capitania do RS apud MONQUELAT (2010).

${ }^{19}$ Requerimento de 30.09.1789, AHU-ACL-CU-019, Cx. 3, Doc. 238 (Projeto Resgate).

${ }^{20}$ Ofício de Francisco de Souza Coutinho a Martinho de Melo e Castro (Pará, 11.10.1792). Coleção Carvalho, Seção Manuscritos, Biblioteca Nacional do Rio de Janeiro.

${ }^{21}$ Requerimento de 07.08.1801, AHU-ACL-CU-019, Cx. 5, Doc. 394 (Projeto Resgate).

${ }^{22}$ Requerimento de 23.10.1805, AHU-ACL-CU-019, Cx. 10, Doc. 605 (Projeto Resgate).

${ }^{23}$ Segundo palavras do Vice-Rei, Medina "havia descoberto o segredo e as carnes rioplatenses venceram o mito de suas condições inferiores, pois jamais haviam obtido antes a cor e a consistência das do norte". O segredo, conforme ele, nada mais era do que "la salmuera del barril com una corta dosis de sal nitro” (MONQUELAT, 2010, p. 80).

${ }^{24} \mathrm{Na}$ realidade, como demonstrou Montoya, estas carnes pareciam estar sendo exportadas desde o século XVII, mas em quantidades muito pequenas, ainda em caráter experimental e com grandes intervalos de tempo (MONTOYA, 1956). ${ }^{25}$ Conforme Sluyter, o produto final tinha várias características vantajosas em relação a outras formas de carne conservadas. A maior secura do charque com relação à carne salgada reduziu tanto o peso e o volume a menores custos de transporte. A maior secura também permitiu o carregamento a granel em porões de navios e a preservação do produto para muitos meses após a sua fabricação, mesmo em climas tropicais (SLUYTER, 2010, p. 106).

${ }^{26} \mathrm{Em}$ 1778, um funcionário da Coroa portuguesa recomendou a producão das "carnes salgadas que devem ser exportadas a este reino em lugar das que vem 
da Irlanda", e o cultivo do linho cânhamo, que substituiria as importações da Rússia (GUTIERREZ, 2001, p. 53).

${ }^{27}$ Ofício de Francisco de Souza Coutinho a Martinho de Melo e Castro (Pará, 11.10.1792). Coleção Carvalho, Seção Manuscritos, Biblioteca Nacional do Rio de Janeiro.

${ }^{28} \mathrm{O}$ corpo mercantil portenho era composto por imigrantes vindos do País Basco, de Castela, da Galiza e de Santander, além de um grande contingente de nascidos na América. Eles constituiram-se nos maiores beneficiários das reformas bourbônicas e passaram a controlar um comércio crescente que ligava Buenos Aires a Montevidéu, Assunção, Córdoba, Tucuman, Jujuy, Salta, Potosi e outras as áreas de mineração andinas, além do Chile (SOCOLOW, 1975, p. 1-2).

\section{Referências}

ALADREN, Gabriel. Sem respeitarfé nem tratados: escravidão e Guerra na formação histórica da fronteira sul do Brasil (Rio Grande de São Pedro, c. 1777-1835). Dissertação (Doutorado em História)-UFF, PPG-História, 2012.

ALDEN, Dauril. El Brasil colonial tardio (1750-1808). In: BETHELL, Leslie (Org.). Historia de America Latina. Barcelona: Editorial Critica, v. 3, 1990, p. 306-357.

BELL, Stephen. Early industrialization in the South Atlantic: political influences on the charqueadas of Rio Grande do Sul before 1860. Journal of Historical Geography, v. 19, n. 4, jul. 1993, p. 400.

BLACKBURN, Robin. A construção do escravismo no novo mundo: do Barroco ao Moderno (1492-1800). Rio de Janeiro: Record, 2003.

BORUCKI, Alex. Notas sobre el trafico de esclavos al Río de la Plata durante el siglo XVIII. Revista Latino-americana de Estudos Avançados, v. 1, n. 1, jan/jun., 2016, p. 7-28.

BORUCKI, Alex; ELTIS, David; WHEAT, David. Atlantic History and Slave Trade to Spanish America. American Historical Review, n. 120, abr. 2015, p. 433-461.

BRADING, D. A. La España de los Borbones y su imperio americano. In: BETHELL, Leslie (Org.). Historia de America Latina. Barcelona: Editorial Critica, v. 2, 1990, p. 85-126.

BRAUDEL, Fernand. Civilização Material, Economia e Capitalismo: Os Jogos das Trocas. São Paulo: Martins Fontes, 1996. 
"Os segredos da carne": o mercado atlântico das carnes secas...

CASTELLANOS, Alfredo. Breve historia de la ganadería en el Uruguay. Montevidéu: Banco de Crédito, 1971.

CHAVES, Antônio José Gonçalves. Memórias ecônomo-políticas sobre a administração pública do Brasil. Porto Alegre: Cia. União de Seguros Gerais, 1978.

CHIARAMONTE, Jose Carlos. La dimensión atlántica e hispanoamericana de la Revolución de Mayo. Boletín del Instituto de Historia Argentina y Americana Dr. Emilio Ravignani, Buenos Aires, n. 33, jan./dez. 2011.

FLORENTINO, Manolo. Em costas negras: uma história do tráfico atlântico de escravos entre a África e o Rio de Janeiro (séculos XVIII e XIX). São Paulo: Companhia das Letras, 1997.

GARAVAGLIA, Juan Carlos. De la carne al cuero: los mercados para los productos pecuarios (Buenos Aires y su campaña, 1700-1825). Anuario del IEHS, Tandil, n. 9, 1994, p. 61-95.

GIBERTI, Horacio. Historia Económica de la ganadería argentina. Buenos Aires: Solar, 1981.

GUTIERREZ, Ester J. B. Negros, charqueadas \& olarias: um estudo sobre o espaço pelotense. Pelotas: UFPel, 2001.

HOBSBAWM, Eric. A Era das Revoluçoes: Europa (1789-1848). Rio de Janeiro: Paz e Terra, 2009.

HORTA, José. O comércio do sal português com a Irlanda no século XIX: uma leitura geográfica.In: SEMINÁRIO INTERNACIONAL SOBRE O SAL PORTUGUÊS, 1., 2005, Portugal. Anais... Porto: Universidade do Porto, 2005. p. 297-310.

IOMAIRE, Máirtín Mac Con; GALLAGHER, Pádraic Óg. Irish Corned Beef: a Culinary History. Dublin Institute of Technology, Articles, 2011.

KÜHN, Fábio. Clandestino e ilegal: o contrabando de escravos na Colônia do Sacramento (1740-1777). In: XAVIER, Regina (Org.). Escravidão e liberdade: temas, problemas e perspectivas de análise. São Paulo: Alameda, 2012, p. 179-206.

LINEBAUGH, Peter; REDIKER, Marcus. A bidra de muitas cabeças: marinheiros, escravos, plebeus e a história oculta do Atlântico revolucionário. São Paulo: Companhia das Letras, 2008.

MAGALHÃES, Manoel Antônio de. Almanack da Vila de Porto Alegre. In: FREITAS, Décio. O capitalismo pastoril. Porto Alegre, Escola Superior de Teologia São Lourenço de Brindes, 1980. 
MALERBA, Jurandir. A Independência brasileira: Novas Dimensões. Rio de Janeiro: FGV, 2006.

MANDELBLATT, Bertie. A Transatlantic Commodity: Irish Salt Beef in the French Atlantic World. History Workshop Journal, n. 63, 2007, p. 21.

MARQUES, Alvarino da Fontoura. Episódios do Ciclo do Charque. Porto Alegre: Edigal, 1987.

MARQUESE, Rafael de B. Feitores do corpo, missionários da mente: Senhores, letrados e o controle dos escravos nas Américas (1660-1860). São Paulo: Cia. das Letras, 2004.

MENZ, Maximiliano. Entre impérios: formação do Rio Grande na crise do sistema colonial português (1777-1822). São Paulo: Alameda, 2009.

MONQUELAT, A. F. Desfazendo mitos (notas à história do Continente de São Pedro). Pelotas: Ed. Livraria Mundial, 2012.

MONQUELAT, A. F. Senhores da carne: charqueadores, saladeristas y esclavistas. Pelotas: Ed. Universitária/UFPel, 2010.

MONTOYA, Alfredo. Historia de los saladeros argentinos. Buenos Aires: Ed. Raigal, 1956.

MONQUELAT, A. F.; MARCOLLA, V. Charque, charqueadas e charqueadores no primeiro período (1780-1800). Diário da Manhã, Pelotas, 23 ago. 2010.

OSÓRIO, Helen. O império português no sul da fronteira: estancieiros, lavradores e comerciantes. Porto Alegre: UFRGS, 2007.

PIMENTA, João Paulo G. Estado e Nação no fim dos impérios ibéricos no prata (18081828). São Paulo: Editora Hucitec/Fapesp, 2002.

PINTOS, Anibal Barrios. Montevideo: Los Barrios (I). Montevideo: Ed. Nuestra Tierra, 1971).

PINTOS, Anibal Barrios. Historia de la ganedería en el Uruguay (1574-1971). Montevidéu: Biblioteca Nacional, 1973.

PRADO, Fabrício. In the shadows of empires: trans-imperial networks and colonial identity in Bourbon Río de la Plata. Diss. (Ph.D.) - Emory University, 2009.

RINKE, Stefan; SCHULZE, Frederik. Los orígenes de las revoluciones de independência de America Latina em perspectiva atlântica. Estudos IberoAmericanos, v. 36, n. 2, 2010, p. 153-178. 
RODRIGUES, Jaime. Um perfil de cargos e funções na Marinha mercante luso-brasileira (séculos XVIII e XIX). Revista Anos 90, Porto Alegre, v. 22, n. 42, 2015, p. 295-324.

ROLIM, Leonardo. "Tempo das carnes" no Siará Grande: dinâmica social, produção e comércio de carnes secas na Vila de Santa Cruz do Aracati (c. 1690 - c. 1802). Dissertação de Mestrado, UFPB, 2012.

ROSAL, Miguel A.; SCHMIT, Roberto. Del Reformismo colonial Borbónico al librecomercio: las exportaciones pecuárias del Río de La Plata (1768-1854). Boletín del Instituto de Historia Argentina y Americana, n. 20, 2a sem., 1999, p. 69-109.

SCHWARTZ, Stuart. Segredos Internos: engenhos e escravos na sociedade colonial (1550-1835). São Paulo: Companhia das Letras, 1999.

SLUYTER, Andrew. The Hispanic Atlantic's Tasajo Trail. Latin American Research Review, v. 45, n. 1, 2010.

SOCOLOW, Susan M. Economic Activities of the Porteño Merchants: the Viceregal Period. The Hispanic American Historical Review, v. 55, n. 1, Feb. 1975, p. 1-24.

TREUDLEY, Mary. The United States and Santo Domingo (1789-1866). The Journal of Race Development, v. 7, n. 1, jul., 1916, p. 83-145.

TRUXES, Thomas M. Irish-American Trade (1660-1783). Cambridge University Press, 1988.

VARGAS, Jonas M. Pelas margens do Atlântico: um estudo sobre elites locais e regionais no Brasil a partir das famílias proprietárias de charqueadas em Pelotas, Rio Grande do Sul (século XIX). Tese de Doutorado, UFRS, 2013.

VARGAS, Jonas M. Abastecendo plantations: A inserção do charque fabricado em Pelotas (RS) no comércio atlântico das carnes e a sua concorrência com os produtores platinos (século XIX). História (UNESP), v. 33, n. 2, 2014, p. 540-566.

WALTON, Gary M. The economic rise of early America. Cambridge University Press, 1979, p. 81-82, p. 193.

XAVIER, Paulo. Salgas de carne. Correio do Povo, Porto Alegre, 15 mar. 1974, p. 9.

Recebido em: 12/12/2016 Aprovado em: 01/03/2017 